\title{
O clã Malucelli - trajetória, empreendimento e principais atores no \\ Paraná
}

\author{
Nicolas Paes Coelho ${ }^{1}$
}

RESUMO: O trabalho apresenta a atuação da família Malucelli em território paranaense desde a chegada de Giovanni Malucelli e família em 1877 até os dias atuais. Passando por todas as gerações, são levantados dados sobre os principais membros, como relações que estabeleceu e atividades que desenvolveu, seja na indústria e comércio ou no campo político.

Palavras-chave: Malucelli. Genealogia. Trajetória. Paraná. Empreendimentos. Relações.

\section{The Malucelli clan - trajectory, enterprise and main actors in Paraná}

ABSTRACT: The work presents the performance of the Malucelli family in Paraná territory since the arrival of Giovanni Malucelli and family in 1877 until the present day. Passing through all generations, data are collected on key members such as relationships that he established and activities he developed, whether in industry and commerce or in the political field.

Keywords: Malucelli, Genealogy. Trajectory. Paraná. Entrepreneurship. Relationships

- Enviado em 01/05/2017

- Aprovado em 17/05/2017

${ }^{1}$ Graduando de Ciências Sociais na UFPR. Uma versão preliminar desse texto foi apresentada no VIII Seminário Nacional de Sociologia e Política realizado de 17 a 19 de maio de 2017 na UFPR. E-mail: nicolaspaes94@gmail.com 


\section{INTRODUÇÃO}

A Família Malucelli possui um histórico de tradição no estado do Paraná, especialmente na região de Morretes onde mantem suas raízes. Esse artigo pretende tratar os principais nomes do clã ao longo desses 140 anos de história (1877-2017) e destacar seus feitos no estado do Paraná. A trajetória da família remete principalmente à empreendimentos e cargos políticos, possuindo uma grande quantidade de figuras importantes que atuaram em diversas áreas no estado. O artigo está estruturado de maneira a tratar cada geração da família destacando os principais nomes e contribuições para o estado do Paraná. Atualmente o 'Grupo JMalucelli' pode ser considerado o maior feito da família no sentido de empreendimento, afinal é um conglomerado que possui 80 empresas e atua nos mais variados setores, incluindo uma empreiteira responsável por grandes obras públicas, a JMalucelli Construtora de Obras. Outras duas importantes empresas do grupo são Paraná Banco e JMalucelli Seguradora, responsáveis por bons números no lucro do conglomerado. Seu fundador, Joel Malucelli, é filiado ao PSD e atua na política como primeiro suplente de senador, estendendo também conexões nessa esfera através do casamento de sua filha Paola Malucelli com o deputado federal João Arruda, sobrinho do exsenador Roberto Requião.

Primeiro verifica-se as atividades dos primeiros Malucelli em terras paranaenses, e geração por geração se destaca quais foram os empreendimentos que desenvolveram e que incentivo receberam do governo da época. Para finalmente chegarmos nos dias atuais, onde são analisadas com atenção as relações sociais e as empresas da família, juntamente com as parcerias firmadas e principais conexões políticas.

\section{ORIGEM E CHEGADA DA FAMÍLIA NO BRASIL}

O sobrenome Malucelli é originário do Norte da Itália, é um apelido e em uma tradução aproximada significa "pequeno pássaro ruim". Antônio Marcos Pereira pesquisou sobre a família 
Malucelli e contribui com importantes informações em seu blog sobre a história da família, o pesquisador é membro do clã por parte de mãe (Helena Malucelli). No Brasil, Giovanni Malucelli foi o pioneiro do sobrenome, nascido em Dueville, uma cidade na província de Vicenza no norte da Itália, chegou ao Brasil pelo porto de Paranaguá no dia 1 de abril de 1877 com sua esposa Margherita Malucelli e seus oito filhos: Marco Antônio (17 anos), Giustina (15), Baptista (13), Lucia (11), Lourenço (9), João (6), Antônio (3) e Domingos (1). ${ }^{2}$ Giovanni era filho de Marco Antônio Malucelli e Giustina Guidolin, na Itália trabalhava como agricultor com a família e nessa época, o continente europeu registrava um aumento populacional cada vez maior, o que gerava a desvalorização do salário e o desemprego. Regiões como o norte da Itália, berço dos Malucelli, sofriam com a pouca qualidade de vida e conviviam com a fome, porém, a família Malucelli vivia com certo conforto e possuía um abastecimento considerável, segundo o pesquisador Antônio Marcos Pereira. ${ }^{3}$ Nesse período vinha acontecendo a grande emigração europeia, onde milhões de pessoas saem do Velho Continente para o Novo Mundo e Giovanni Malucelli vê nisso uma oportunidade. Um ano após chegar falece vítima de malária. Sua esposa Margherita solicita então a vinda de dois sobrinhos residentes na Itália: Marco (com sua esposa Anda de Bassi) e Domênico (com sua esposa Margherita Fellipi e seu filho Lorenzo). Esses são os primeiros Malucelli em terra paranaense.

Estabeleceram-se a princípio na colônia de Alexandra, litoral paranaense, juntamente com várias outras famílias italianas. Na época havia um incentivo do governo da província em estimular a vinda de estrangeiros para trabalhar em colônias agrícolas com a finalidade de abastecer os centros urbanos, porém, os italianos encontraram ali condições que desfavoreceram seu progresso, visto que o clima era muito quente e doenças tropicais causadas por insetos adoeciam membros da colônia. Insatisfeitos, grande parte dos imigrantes buscaram outras regiões do estado, sendo que os Malucelli se mudaram para a colônia Nova Itália, em Morretes.

Os irmãos Marco Antônio e Baptista trabalharam na construção da estrada de ferro no trecho entre Morretes e Pinhais, enquanto os outros irmãos desempenhavam atividades agrícolas como a plantação de cana-de-açúcar e banana, além do corte e venda de lenha. O

\footnotetext{
${ }^{2}$ Correio do Paraná. 09/05/1964. Página 8, Centenário de nascimento de Baptista Malucelli.

3 Disponível em: http://triaquimmalucelli.blogspot.com.br/2013/06/origens-da-familia-malucelli.html. Acesso 13.maio.2017.
} 
desenvolvimento dessas atividades permitiu que a família comprasse o Engenho Central de Morretes, localizado na Colônia Nova Itália. A aquisição possibilitou a família aumentar seus ganhos e com o tempo os Malucelli expandiram suas atividades, atuando na indústria, comércio, pecuária e agricultura. Marco Antônio Malucelli passa a ser então o imigrante italiano mais rico na colônia Nova Itália, sendo convidado pelo coronel Rómulo José Pereira para ingressar no partido Republicano, pelo qual foi vereador e presidente da Câmara até $1927 .{ }^{4}$ Marco Antônio é o primeiro membro do clã a atuar em um cargo público, expandindo as relações da família no campo da política logo nos primeiros anos em território paranaense, mantendo assim relações empresariais e políticas que significam 'portas abertas' para a família, afinal, redes de interesses e troca de favores são relações que duram e atravessam décadas.

No ano de 1908, a viúva Margherita Malucelli faleceu, naquele momento todos os membros viviam em dois sobrados no Sitio Grande em Morretes. Marcos Malucelli \& Irmãos Ltda foi a primeira empresa que levou o nome do clã, produzindo bebidas e engarrafando na propriedade da família. Percebe-se nesse momento que o clã já possuía algumas aquisições de relevância, por exemplo, produção e engarrafamento de bebidas pra época era um processo difícil, visto que normalmente quem produzia não engarrafava e vice-versa. Até 1923 toda a família se encontrava unida em torno da firma Marcos Malucelli e Irmãos Ltda, com exceção de Antônio Malucelli, que se desligou dos irmãos. Posteriormente em 1947, a firma passa a produzir açúcar. ${ }^{5}$

Os Malucelli foram os primeiros moradores de Morretes a terem energia elétrica e água encanada, a família instalou uma roda d'água na casa de Marco Malucelli e posteriormente os outros moradores da cidade vieram a usufruir do benefício. Foram também os primeiros a possuir automóvel e telefone na região. Esses são indícios da importância e influência que a família exercia, sendo citados e recebendo homenagens com frequência em jornais da época.

\footnotetext{
4 Disponível em: http://triaquimmalucelli.blogspot.com.br/2013/06/imigracao-italiana-em-morretes.html. Acesso 13.maio.2017.

${ }^{5}$ Diário do Paraná. 15/09/1947. Página 4, Açúcar paranaense.
} 
Em 1912, Arlindo Bessa, representante da Mutua Constructora, viaja para Morretes e conquista a adesão de novos sócios para sua empresa, entre esses nomes estão: Baptista Malucelli, João Malucelli, Domingos Malucelli e Lourenço Malucelli. ${ }^{6}$

O Paraná vivenciou uma forte geada no ano de 1918, e o canavial dos Malucelli foi fortemente afetado, obrigando os vários membros da família a se dispersarem em território paranaense, firmando-se em novas áreas com suas famílias e firmas, expandindo seus negócios e áreas de atuação. Nesse momento grande parte dos membros da família já participava em um empreendimento, porém quem merece destaque é Baptista Malucelli, que nessa época mudou-se para Palmeira inaugurando uma indústria de madeiras, fábrica de compensados, caixas e móveis, serrarias e uma fábrica de confecção de roupas na capital. Baptista teve os seguintes filhos: João Baptista, Angelina, Lucia, Marcos Baptista, Vicente Baptista, Emilio, Benjamin, Marina, Maria Itália e Maria Cândida.

\section{NETOS DO PIONEIRO E SUAS PRINCIPAIS ATIVIDADES}

Em 1930 os irmãos Benjamin, Marcos, Vicente e Emílio Malucelli adquiriram um vasto território em Pinheiral de Baixo, Palmeira-PR. Devido à escassez de arvores na região de Três Morros mudaram sua serraria para a nova região. Estabeleceram-se ali e graças a abundância de matéria prima a serraria prosperou, ao redor se formou uma vila com escola, armazém, igreja e um clube. Com a expansão da serraria vieram outras quatro (Poço Grande, Queimadas, São João do Triunfo e Vitorinópolis), exportando produtos para Inglaterra e Dinamarca. O prefeito da cidade de Palmeira na época foi Benjamin Malucelli, um dos proprietários das serrarias. Isso demonstra a influência que o clã exercia na região. A firma permaneceu durante décadas na área até que se esgotou a matéria prima e, somado a falhas administrativas, causou a falência do negócio. o sr.

\footnotetext{
${ }^{6}$ A República. 27/06/1912. Página 1, Notas.
} 
Reni Malucelli afirma: "Nunca se pensou em reflorestamento porque na época existia o INP Instituto Nacional do Pinho, governamental, que controlava a quantidade de Pinheiro cortado". ${ }^{7}$

O INP foi um órgão criado em 1941 e atuava como protetor do interesse dos produtores, industriais e exportadores de pinho, regulamentava a atividade a partir de cadastros, fixação de preços, fiscalização e era responsável por reflorestar as áreas exploradas. Tanto o INP quanto os empresários da madeira não agiram com responsabilidade e a vasta área da região de Palmeira foi devastada. Várias foram as criticas feita por ex-moradores da localidade, protestando contra as ruinas em que hoje se encontram a área. A partir dessa situação é possível compreender a atuação dos empresários da madeira no território paranaense. Os Malucelli já haviam migrado da região de Três Morros para Palmeira devido à escassez de madeira na região anterior e devido à exploração irracional da matéria prima regional, devastaram também a nova região.

O neto do pioneiro Giovanni Malucelli que merece destaque foi Benjamin Malucelli, três vezes prefeito de Palmeira-PR, concorreu e venceu em 1947, ano em que se voltou a eleição para prefeitos no Brasil. Venceu também em 1955 e 1968. Como prefeito construiu o prédio que abriga o setor administrativo e o gabinete do prefeito até os dias de hoje, construiu também o Cine Teatro Municipal. ${ }^{8}$

Luiz Malucelli, filho de Luiz e Jandyra Brambilla, neto de Antônio e Rosa Zilli. Nasceu dia 20 de outubro de 1937 em Morretes/PR. Trabalhava na madeireira da família e na década de 60 foi convidado pelo então governador Ney Braga para ser secretário do governo. A partir disso passa a ser candidato à vereador e em seguida elegesse o deputado estadual mais novo do Brasil, com 30 anos de idade. Formado em direito, foi procurador do estado durante 37 anos. $^{9}$

João Malucelli Junior era primo dos proprietários das serrarias, nasceu em 23 de julho de 1916, começou trabalhando na usina de açúcar da família. Posteriormente se mudou para capital, já

\footnotetext{
${ }^{7}$ Disponível em: $\quad$ http://pinheiraldebaixo.blogspot.com.br/2011/11/pinheiral-dos-maluceliserraria.html. Acesso 13.maio.2017.

8 Disponível em: http://www.gazetadepalmeira.com.br/eleicoes/benjamin-malucelli-conquista-o-seu-primeiromandato-de-prefeito-em-1947/. Acesso 13.maio.2017.

${ }^{9}$ Livro: Família Malucelli: uma história de imigração. Página 75
} 
casado com Helena Hauagge Malucelli, onde abriu uma madeireira e fábrica de móveis em Curitiba e região. Ao longo da vida teve sete filhos. ${ }^{10}$

\section{PRÓXIMA GERAÇÃO E SEUS PRINCIPAIS DESTAQUES}

Muitos são os bisnetos de Giovanni Malucelli, analisaremos aqui os que se sobressaíram, como os irmãos Marcos e Sergio Malucelli. Marcos nasceu em Iraty dia 22/09/1950, é sócio do escritório de advocacia Malucelli Advogados e presidiu o Clube Atlético Paranaense de 2009 a 2011. Atuou em diversas funções administrativas e jurídicas no clube e em 2001 seu escritório era o responsável pelas causas cíveis que envolviam o Atlético. ${ }^{11}$ No dia 24/04/2017 Marcos foi expulso do quadro associativo do Clube Atlético Paranaense após decisão do Conselho Deliberativo do clube. O Conselho afirma que Marcos Malucelli ofendeu o estatuto do Atlético Paranaense quando em 2011 contratou o uruguaio Morro Garcia e Marcos em sua defesa afirma: "Foi uma negociação normal, o clube tinha dinheiro, pagou, tanto que o Judiciário considerou legal. Mas o tribunal do Petraglia achou que não". ${ }^{12}$

Sergio Malucelli é um importante empresário que atua no futebol paranaense, dono da SM Sports, empresa que possui Centro de treinamento com uma das melhores estruturas do Brasil e gerencia o Londrina Esporte Clube, clube de futebol que preside atualmente. Presidiu também o Iraty Sport Club até 2011, quando assumiu o Londrina, participou também da administração do Atlético Paranaense no inicio da gestão Petraglia. Sergio é um conhecido amigo do treinador Wanderley Luxemburgo, de quem foi sócio em um bar e uma fabrica de isotônicos em Curitiba nos anos $90 .{ }^{13}$ É possível observar como os Malucelli estiveram envolvidos com o futebol ao longo dos

\footnotetext{
${ }^{10}$ Disponível em: http://www.parana-online.com.br/editoria/cidades/news/190724/. Acesso 13.maio.2017.

${ }^{11}$ Disponível em: http://www.furacao.com/historia/presidentes/malucelli.php. Acesso 13.maio.2017.

12 Disponível em: http://www.tribunapr.com.br/esportes/atletico/sem-perdao-marcos-malucelli-e-expulso-doatletico/. Acesso 13.maio.2017.

13 Disponível em: http://www.infoesporte.com.br/noticias/figueirense/fora-de-campo/29072015/conheca-sergiomalucelli-e-juan-figer-homens-fortes-do-novo-figueira/. Acesso 13.maio.2017.
} 
anos, os irmãos Marco e Sergio demonstraram grande envolvimento no futebol paranaense e em seus negócios esportivos.

Luiz Malucelli Neto, filho de Luiz Malucelli e Regina Volpi, nasceu em 14/04/1961 em Curitiba/PR. Teve dois filhos. Entre os anos de 1981 e 1986 trabalhou na Banestado Corretora de Valores, na Tibagi Distribuidora de Valores e Paraná Financeira, nos anos de 1986 e 1987 foi assessor do Governador João Elísio Ferraz de Campos. Assumiu a superintendência da FIEP de 1997 a 2001. Concorreu a deputado estadual e ficou com a quarta suplência em 2002 com aproximadamente 28400 votos. Em 2004 trabalhou poucos meses na chefia do gabinete de Cassio Taniguchi e em 2006 assume a superintendência da Secretária de Governo. Em 2007, era terceiro suplente e assume a vaga do deputado Rui Hara na Assembleia Legislativa Paranaense, que na ocasião passou a assumir uma secretária na Prefeitura de Curitiba $\cdot{ }^{14}$ Declarações de Luiz Malucelli Neto, que aparecem no livro "Familía Malucelli: uma história de imigração" da autora Lorena Malucelli Pelanda, ilustram com precisão alguns pontos que busco frisar nesse artigo:

Eu nasci com política em casa. Meu avô por parte de mãe também era político. Por coincidência fui gostando. Mas, eu confesso, infelizmente, que é uma frustração, que nas duas eleições não conseguimos nos eleger, só consegui a primeira suplência. Fizemos votação superior a muitos que se elegeram, mas a legenda não nos permitiu entrar. Agora chega de política!

O parentesco de Luiz Malucelli Neto já incluía políticos e homens públicos desde sempre, a família Malucelli esteve presente na esfera pública paranaense desde muitos anos e estabeleceu vínculos que possibilitam o ingresso de outros de seus membros na atividade política. As conexões estabelecidas entre a estrutura de parentesco e a estrutura política rendem parcerias, acordos e favores que atravessam o tempo e estendem-se por anos, logo, a política está presente desde muito cedo na vida de Luiz Malucelli Neto e facilita sua entrada na disputa eleitoral posteriormente. Nesse sentido, Luiz é muito preciso em outra de suas declarações: “A família Malucelli é uma senha. Você acaba abrindo portas com o sobrenome. Em todos os lugares que

\footnotetext{
${ }^{14}$ Disponível em: http://www.plantaodacidade.com.br/Anteriores/terca030707/tviii.htm. Acesso 13.maio.2017.
} 
encontrei um Malucelli fui sempre bem recebido. Sempre acabamos achando apoio e um parente em comum."15

Outro membro dessa geração da família que ganhou algum destaque foi Sergio Luiz Malucelli, filho de Orlando e Zulmira Pedrosa. Nascido em Morretes, é Coronel da Policia Militar, presidente da FETRANSPAR (Federação das empresas de Transporte de Cargas do Estado do Paraná) ${ }^{16}$ e assumiu em março de 2017 a presidência do SEST (Serviço Social do Transporte) e o SENAT (Serviço Nacional de Aprendizagem do Transporte) pelos próximos 4 anos. ${ }^{17}$ No ano de 1996 assumiu como interventor da prefeitura de Morretes, cargo que terminou no final do mesmo ano.

Nascido em 1945, Joel Malucelli é filho de João Malucelli Junior e Helena Hauagge Malucelli. É um dos principais nomes do empresariado paranaense, fundador do 'grupo JMalucelli': um conglomerado de 84 empresas de diferentes segmentos, desde Clube de Futebol, Seguradoras, Construtora, Produção de energia até veículos de comunicação e o Paraná Banco. Além disso, presidiu o Coritiba Foot Ball Club entre 1996 e 1997.

A primeira empresa do grupo nasce em 1966: JMalucelli Costrutora de Obras Ltda, vejamos a fala do sr. Joel sobre seu início de carreira, em entrevista concedida à revista Imóvel Magazine ${ }^{18}$ :

\begin{abstract}
"Com 19 anos meu pai me emancipou para que eu pudesse montar minha primeira empresa. Era a Sociedade Paranaense de Engenharia e Empreendimentos Ltda.. Eu comecei com apenas aquele trator. Meu primeiro trabalho foi fazer uma estrada no norte velho do Paraná. Lá já foi um contrato direto com o DER na época".
\end{abstract}

Vejamos agora um trecho da fala de Joel Malucelli em depoimento à Memórias Paraná sobre o momento em que recebeu o aluguel de sua máquina: "No primeiro dia que a máquina trabalhou 10 horas, que veio o boleto da produção, eu senti que ia ficar rico, porque aquele aluguel

\footnotetext{
${ }^{15}$ Disponível no livro "Família Malucelli: uma história de imigração" de Lorena Malucelli Pelanda

16 Disponível em: http://paranaportal.uol.com.br/economia/sergio-malucelli-segue-na-presidencia-da-fetransparpelos-proximos-quatro-anos/. Acesso 13.maio.2017.

17 Disponível em: http://paranaportal.uol.com.br/colunas-sintonia-fina/malucelli-assumira-sest-e-senat/. Acesso 13.maio.2017.

18 Disponível em: http://www.imovelmagazine.com.br/materias/2011/11/o-poder-da-multiplicacao-C109164.html. Acesso 13.maio.2017.
} 
daquela máquina naquele dia representava mais do que eu ganhava no mês todo, que era meu salário na Copel."

Como constatado, o pai de Joel, João Malucelli Junior era proprietário de fábricas em Curitiba e região, além de seus parentes quase sempre estarem envolvidos em empresas, o que significa um ambiente familiar com preocupações e questões acerca dos negócios, um ambiente assim ajuda na formação do empresário. Outra observação importante que nos ajuda a pensar a trajetória de Joel Malucelli diz respeito à presença do Estado com contratos e oportunidades. Um empresário só alcança um grande patamar se auxiliado pelo Estado, a ideia de self-made man, ou homem que se fez por conta própria não se mostra verdadeira nesse sentido.

A segunda empresa do grupo foi uma corretora de câmbio e valores, onde Joel Malucelli aplicava seu próprio dinheiro comprando títulos, e a terceira empresa surge a partir de uma oportunidade do governo: "Na época o governo instituiu um plano de reflorestamento do Brasil, então quem reflorestava pagava menos imposto de renda, ai eu criei a JMalucelli Florestal". ${ }^{19}$

Uma das principais empresas do grupo hoje é o Paraná Banco, que possui mais de 530 mil clientes, conta com mais de 414 postos de atendimento e em 2014 teve um lucro líquido recorrente de 150 milhões sendo que seu patrimônio aproxima-se de 1,4 Bilhão. 0 presidente do grupo é Cristiano Malucelli, filho de Joel. ${ }^{20}$

O ramo da comunicação também é um dos pontos fortes do conglomerado, pois possuem 4 rádios: CBN, Radio Globo, Band News e CBN em Maringá, detêm a TV bandeirantes em Curitiba e Maringá, possuem o jornal 'O Metro' em Curitiba, considerado o maior jornal do mundo estando presente em 22 países e 131 cidades, além de seu último investimento o Paraná Portal.21

Uma das maiores paixões de Joel Malucelli e família sempre foi o futebol, a ponto de fundarem em 1998 o Malutrom S.A (Malutrom é a combinação do nome das duas famílias: Malucelli e Trombini). Foi o primeiro clube-empresa do Brasil através da Lei Pelé. Em 2009 firmou

\footnotetext{
${ }^{19}$ Disponível em: http://memoriasparana.com.br/2016-joel-malucelli/. Acesso 13.maio.2017.

20 Disponível em: https://www.paranabanco.b.br/institucional/Paginas/conheca-o-parana-banco.aspx. Acesso 13.maio. 2017 .

21 Disponível em: http://paranaportal.uol.com.br/politica/richa-antecipa-vinda-de-duas-montadoras-ao-parana-cominvestimentos-de-r-12-bilhoes/. Acesso 13.maio.2017.
} 
parceria com o Corinthians Paulista em um acordo que envolvia troca de jogadores e técnicos, além da alteração no nome do clube paranaense para Corinthians Paranaense. A parceria durou 3 anos e após encerrada o clube passa a chamar-se JMalucelli Futebol. ${ }^{22}$ No ano de 2017 o clubeempresa foi punido no campeonato paranaense com a perda de 16 pontos após escalação irregular de um atleta, causando o rebaixamento do time. ${ }^{23}$ Essa decisão fez Joel cogitar fechar as portas do clube. ${ }^{24}$

Algumas outras empresas do grupo são: JMalucelli Incorporações, JMalucelli Equipamentos, JMalucelli Rental, JMalucelli Energia, JMalucelli Concessões, JMalucelli \& CMC ambiental, Fundo Paraná, JMalucelli Previdência, JMalucelli Investimentos, JMalucelli Controle de riscos, JMalucelli Seguros, JMalucelli Seguradora, JMalucelli Resseguradora, Centro de Serviços Compartilhados, Expo Renault Barigui, Park Shopping Barigui, Hotel Villa Real em Guaratuba e São Francisco, Instituto Joel Malucelli e JMalucelli Agro-Pastoril del Uruguai.

A família Malucelli sempre esteve acompanhada em seus negócios pela família Trombini, além das parcerias empresariais vários casamentos entre os dois clãs são possíveis de se verificar. A JMalucelli Construtora de Obras tem em seus cargos de diretoria e chefia as seguintes famílias: Prosdócimo, Moro, Scarante e Jacomel. Todas famílias da elite paranaense e que ao longo da história estiveram juntas em negócios, mostrando que existe uma rede de relações até certo ponto fechadas entre seus membros e suas firmas.

O nome de Joel Malucelli já foi cotado para candidato à prefeitura de Curitiba e mesmo para candidato à governador. Joel atualmente é filiado ao PSD e é primeiro suplente do senador Álvaro Dias (PV). Joel desvinculou-se do PSDB para o PSD, vejamos a razão que o próprio atribuiu para essa troca: "Eu fui pro PSD por consideração que tenho e por ter sido convidado por 3 políticos

\footnotetext{
22 Disponível em: http://www.jmalucellifutebol.com.br/index.php?pag=noticia\&n cod=8108\&titulo=historiacorinthians-paranaense. Acesso 13.maio.2017.

${ }^{23}$ Disponível em: http://globoesporte.globo.com/pr/futebol/campeonato-paranaense/noticia/stjd-extingue-recursode-parana-e-cascavel-e-paranaense-fica-como-esta.ghtml. Acesso 13.maio.2017.

24 Disponível em: http://www.gazetadopovo.com.br/esportes/futebol/campeonato-paranaense/2017/abalado-comtapetao-joel-malucelli-admite-fechar-as-portas-do-jotinha-cder8os0yqlbklpoivefya9lw. Acesso 13.maio.2017.
} 
de primeira linha: um é o deputado Ciarra, outro o deputado Ney Leprevoust e o deputado Reinhold Stephanes". 25

Sobre concorrer à prefeitura ou ao governo do estado, Joel descarta, e afirma como gostaria de atuar:

"Sou suplente de senador, do Álvaro Dias, sou primeiro suplente, estou muito preparado que se um dia ele me der oportunidade de assumir eu vou fazer um trabalho muito legal no senado, porque eu sou uma pessoa que não precisa de votos, não tenho ambição politica, então eu posso propor ao senado coisas que são necessárias e que os políticos às vezes não propõem por que são coisas antipáticas". 26

"Sinto orgulho de ter sido convidado pra ser candidato à governador do estado do Paraná, candidato à prefeito, mas eu acho que do jeito que eu consegui organizar a minha vida eu posso ajudar de outras formas". ${ }^{27}$

No ano de 2016 passou a fazer parte do CDES (Conselho de Desenvolvimento Econômico e Social), o "Conselhão" reativado por Michel Temer e que funciona como um colegiado composto por representantes da sociedade civil que assessoram o Presidente da República em todas as áreas de atuação. ${ }^{28} \mathrm{Em} \mathrm{2017,} \mathrm{Joel} \mathrm{Malucelli} \mathrm{teve} \mathrm{seu} \mathrm{nome} \mathrm{citado} \mathrm{na} \mathrm{delação} \mathrm{da} \mathrm{empresária}$ Mônica Moura na operação Lava-Jato. ${ }^{29}$

As relações do clã na política ainda incluem o casamento da filha de Joel Malucelli, Paola Malucelli com João Arruda, deputado federal e sobrinho de Roberto Requião. Os contatos que a família estabelece com outras famílias da elite no Paraná se estendem para o campo político, onde vão atuar de acordo com seus interesses e de seus semelhantes.

25 Disponível em: https://www.youtube.com/watch?v=zxKO8W6yNSY (jogo do poder 23/10/11). Acesso 13.maio.2017.

${ }^{26}$ Disponível em: http://memoriasparana.com.br/2016-joel-malucelli/. Acesso 13.maio.2017.

${ }^{27}$ Idem

${ }^{28}$ Disponível em: http://www.cdes.gov.br/conselho.html. Acesso 13.maio.2017.

${ }^{29}$ Disponível em: http://extra.globo.com/noticias/brasil/palocci-definia-com-marcelo-odebrecht-valores-de-doacoespor-caixa-2-segundo-monica-moura-21327710.html. Acesso 13.maio.2017. 


\section{FILHOS DE JOEL MALUCELLI, TATARANETOS DO PIONEIRO GIOVANNI}

Joel teve seis filhos: Alexandre Malucelli, Cristiano Malucelli, Monica Malucelli do Amaral, Paola Malucelli de Arruda, Julia Malucelli e Gabriel Malucelli. Os últimos dois filhos são de seu segundo casamento com Miriam Joyce Schmitz Malucelli, empresária sócio proprietária do Vila Real Restaurante LTDA e Umuarama Incorporações LTDA (Gestão e administração de propriedades imobiliárias)..$^{30}$

Alexandre Malucelli é filho de Joel e Solange Elias, casou-se em 2003 com Carolina Gomes, neta do empresário Cesar Gomes, dono da Cerâmicas Portobello. Atualmente Alexandre preside o conglomerado de empresas de seu pai, após anos atuando à frente da Seguradora do grupo. No ramo de seguros é um nome amplamente reconhecido, chegando a presidir o Panamerican Surety Associaction (Associação Panamericana de Fianças) no biênio 2010-2012, tornando-se o segundo brasileiro a assumir esse cargo.31 Sua esposa administra seu negócio chamado 'Mercadoteca', um empreendimento que reúne açougue, peixaria, padaria, hortifrutigranjeiros, empórios e lojas de bebidas como vinhos finos e cervejas em uma área de 3 mil metros quadrados no bairro Campo Comprido de Curitiba. ${ }^{32}$

Cristiano Malucelli casou-se com Stéfani Zago em uma cerimônia amplamente divulgada pela mídia local em uma festa que ocorreu no Castelo Batel. Além de ser presidente do Paraná Banco, Cristiano é diretor presidente dos Hotéis Villa Real, luxuosos hoteis em Guaratuba e São Francisco.

Mônica Malucelli do Amaral é tabeliã desde 09/10/1991 no 6ㅇ Tabelionato de notas, localizado na Rua Emiliano Perneta, 160 - Centro, Curitiba - PR, 80010-050. Também é sócio proprietária da Amare Presentes Especiais, uma loja localizada no Batel que vende artigos para Mesa Posta, Lista de Casamento e Presentes Especiais.

\footnotetext{
${ }^{30}$ Disponível em: http://www.consultasocio.com/q/sa/miriam-joyce-schmitz-malucelli/. Acesso 13.maio.2017.

${ }^{31}$ Disponível em: http://www.sonhoseguro.com.br/2010/05/alexandre-malucelli-assume-comando-da-pasa/. Acesso 13.maio.2017.
}

32 Disponível em: http://www.gazetadopovo.com.br/bomgourmet/mercadoteca-veja-a-lista-dos-16estabelecimentos-confirmados-no-eataly-curitibano/. Acesso 13.maio.2017. 
Paola Malucelli de Arruda é formada em engenharia civil, diretora da JMalucelli Energia, importante empresa do grupo que atua nos ramos de geração, transmissão e comercialização de energia elétrica. Atua nas cinco regiões do país e tem importante participação nos lucros do conglomerado de empresas. É a responsável pelas finanças do grupo. Paola casou-se em 2004 com o atual Deputado Federal João Arruda, sobrinho do conhecido Roberto Requião. Como era de se esperar, a festa teve ampla divulgação da mídia e ocorreu no castelo Batel.

Julia Malucelli é filha do segundo casamento de Joel, com Mirian Joyce Schmitz Malucelli. Estudou na Escola Internacional de Curitiba (2000-2008), é formada em Engenharia Civil pela Universidade Positivo e trabalha no grupo da família como Diretora Administrativa da JMalucelli Comunicações. Além disso, é proprietária junto com seu pai da Julia Malucelli Participações S/A, uma holding de instituições não financeiras, com sede no centro de Curitiba.33

Gabriel Malucelli é o filho mais novo do último casamento de Joel e não desenvolve atividade de relevância que deva ser citada aqui.

\section{CONSIDERAÇÕES FINAIS}

Ao longo dos anos que estiveram em território paranaense, os Malucelli sempre atuaram como empresários e a conclusão que podemos chegar a partir da análise dos dados trabalhados é que prosperaram sempre que amparados pelo Estado. Nos momentos que surgiram oportunidades a partir de incentivos do governo seus negócios obtiveram êxito. São observações importantes quando se entra no debate sobre a existência ou não do empresário 'self-made man', alguém que teria alcançado sucesso e desenvolvido seus negócios apenas com o próprio esforço, sem apoio politico ou qualquer que seja.

A família é conhecida pela tradição no estado, seu nome é citado em homenagens de jornais e clubes da elite paranaense e seus membros mantem conexões importantes na política local. Além disso, estão presentes em diversas áreas da economia, com casamentos entre

\footnotetext{
${ }^{33}$ Disponível em: http://www.consultasocio.com/q/sa/julia-malucelli. Acesso 13.maio.2017.
} 
membros de outros clãs tradicionais, o que forma uma teia de relações entre seus membros. Em relação às empresas que possuíram, é correto afirmar que por sempre empregarem os próprios parentes, construíram um ambiente familiar com hábitos e preocupações que envolvem negócios, servindo como influência e representando uma porta aberta aos membros mais novos que iniciavam a vida no mundo do trabalho e futuramente viriam a ter seus próprios negócios.

\section{REFERÊNCIAS}

Correio do Paraná. 09/05/1964. Página 8, Centenário de nascimento de Baptista Malucelli.

Origens da família Malucelli. Blog Triaquim Malucelli. 09/06/2013. Disponível em: <http://triaquimmalucelli.blogspot.com.br/2013/06/origens-da-familia-malucelli.html> (data de acesso 11/11/2015)

Imigração Italiana em Morretes. Blog Triaquim Malucelli. 09/06/2013. Disponível em: <http://triaquimmalucelli.blogspot.com.br/2013/06/imigracao-italiana-em-morretes.html> (data de acesso 11/11/2015)

Diário do Paraná. 15/09/1947. Página 4, Açúcar paranaense.

A República. 27/06/1912. Página 1, Notas

Pinheiral dos Malucelli/ Serraria. Blog Pinheiral de Baixo. 14/11/2011. Disponível em: <http://pinheiraldebaixo.blogspot.com.br/2011/11/pinheiral-dos-maluceliserraria.html> (data de acesso 12/11/2015)

Benjamin Malucelli conquista o seu primeiro mandato de prefeito em 1947. Gazeta de Palmeira. 12/06/2012. Disponível em: <http://www.gazetadepalmeira.com.br/eleicoes/benjamin- 
malucelli-conquista-o-seu-primeiro-mandato-de-prefeito-em-1947/> (data de acesso $13 / 11 / 2015)$

Pelanda, Lorena Malucelli. Família Malucelli: uma história de imigração. Curitiba/PR: Travessa dos Editores, 2007. Página 75.

Família Malucelli está de luto. Paraná Online. 01/08/2006. Disponível em: <http://www.paranaonline.com.br/editoria/cidades/news/190724/> (data de acesso 02/12/2015)

Presidentes.

Furacão.com.

Disponível

em:

<http://www.furacao.com/historia/presidentes/malucelli.php > (data de acesso 04/02/2016)

'Sem perdão', Marcos Malucelli é expulso do Atletico. Tribuna do Paraná. 27/04/2017. Disponível em: $\quad$ <http://www.tribunapr.com.br/esportes/atletico/sem-perdao-marcos-malucelli-eexpulso-do-atletico/> (data de acesso 04/05/2017)

Conheça Sergio Malucelli e Juan Figer, homens fortes do novo figueira. Infoesporte. 29/07/2015. Disponível em: $\quad$ <http://www.infoesporte.com.br/noticias/figueirense/fora-decampo/29072015/conheca-sergio-malucelli-e-juan-figer-homens-fortes-do-novo-figueira/> (data de acesso 17/03/2016)

Luiz Malucelli Neto toma posse na Assembleia. Plantão Cidade. 03/07/2017. Disponível em: <http://www.plantaodacidade.com.br/Anteriores/terca030707/tviii.htm> (Data de acesso: $15 / 05 / 2017)$ 
Pelanda, Lorena Malucelli. Família Malucelli: uma história de imigração. Curitiba/PR: Travessa dos Editores, 2007. Página 77.

Sergio Malucelli segue na presidência da FETRANSPAR pelos próximos quatro anos. Paraná Portal. 14/11/2016. Disponível em: <http://paranaportal.uol.com.br/economia/sergio-malucellisegue-na-presidencia-da-fetranspar-pelos-proximos-quatro-anos/> (data de acesso: $15 / 05 / 2017)$

Malucelli assumirá SEST e SENAT. Paraná Portal. 10/11/2016. Disponível em: <http://paranaportal.uol.com.br/colunas-sintonia-fina/malucelli-assumira-sest-e-senat/> (Data de acesso: 15/05/2017)

O poder da multiplicação. Imóvel Magazine. 03/12/2011. Disponível em: <http://www.imovelmagazine.com.br/materias/2011/11/o-poder-da-multiplicacaoC109164.html> (data de acesso 03/12/2016)

2016 Joel Malucelli. Memórias Paraná. 11/03/2016. Disponível em: <http://memoriasparana.com.br/2016-joel-malucelli/> (data de acesso :14/04/2016)

Conheça o Paraná Banco. Paraná Banco. Disponível em: <https://www.paranabanco.b.br/institucional/Paginas/conheca-o-parana-banco.aspx> (data de acesso: 01/02/2016)

Richa antecipa vinda de duas montadoras ao Paraná com investimentos de 2BI. Paraná Portal. 10/04/2017. Disponível em: <http://paranaportal.uol.com.br/politica/richa-antecipa-vindade-duas-montadoras-ao-parana-com-investimentos-de-r-12-bilhoes/> (data de acesso: 15/05/2017) 
História-Clube.

JMalucelli

Futebol.

Disponível

em:

<http://www.jmalucellifutebol.com.br/index.php?pag=noticia\&n_cod=8108\&titulo=historiacorinthians-paranaense> (Data de acesso: 14/05/17)

STJD extingue recurso de Paraná e Cascavel e paranaense fica como está. Globoesporte. 11/05/17. Disponível em: http://globoesporte.globo.com/pr/futebol/campeonatoparanaense/noticia/stjd-extingue-recurso-de-parana-e-cascavel-e-paranaense-fica-comoesta.ghtml (data de acesso: 14/05/17)

Abalado com tapetão Joel Malucelli admite fechas as portas do jotinha. Gazeta do Povo. 09/04/17. Disponível em: <http://www.gazetadopovo.com.br/esportes/futebol/campeonatoparanaense/2017/abalado-com-tapetao-joel-malucelli-admite-fechar-as-portas-do-jotinhacder8os0yqlbklpoivefya9lw> (data de acesso: 14/05/17)

Palocci definia com Marcelo Odebrecht valores de doações por caixa 2 segundo Mônica Moura. Extra. 11/05/17. Disponível em: http://extra.globo.com/noticias/brasil/palocci-definia-commarcelo-odebrecht-valores-de-doacoes-por-caixa-2-segundo-monica-moura-21327710.html (Data de acesso: 14/05/2017)

O que é o Conselho. CDES. Disponível em: <http://www.cdes.gov.br/conselho.html> (data de acesso: $15 / 05 / 2017)$

Jogo do poder - Joel Malucelli (23/10/11). Youtube. Publicado em 11/08/2015. Disponível em: https://www.youtube.com/watch?v=zxKO8W6yNSY (Data de acesso 20/12/2015) 
Miriam Joyce Schmitz Malucelli. Consulta Sócio. Disponível em: <http://www.consultasocio.com/q/sa/miriam-joyce-schmitz-malucelli/> (Data de acesso: $15 / 05 / 2017)$

Alexandre Malucelli assume comando da PASA. Sonho Seguro. 25/05/2010. Disponível em: <http://www.sonhoseguro.com.br/2010/05/alexandre-malucelli-assume-comando-dapasa/> (data de acesso: 15/05/2017)

Veja a lista dos 16 estabelecimentos confirmados no eataly curitibano. Gazeta do Povo. $17 / 08 / 2015$. Disponível em: <http://www.gazetadopovo.com.br/bomgourmet/mercadoteca-veja-a-lista-dos-16estabelecimentos-confirmados-no-eataly-curitibano/> (data de acesso: 15/05/2017)

Julia Malucelli. Consulta Sócio. Disponível em: <http://www.consultasocio.com/q/sa/juliamalucelli> (data de acesso: 15/05/2017) 